\title{
Utilization of Emergency Contraception and Associated Factors Among Vocational College Female Students in Shashemene Town, Oromia, Ethiopia, 2018
}

\author{
Hailu Fekadu $^{1,2}$, Buli Teshite ${ }^{1,2, *}$, Getu Teshome ${ }^{1}$, Roza Amdemichael $^{1}$, Mesfin Tafa $^{1}$ \\ ${ }^{1}$ Department of Public Health, Arsi University, Assela, Ethiopia \\ ${ }^{2}$ Shashemene Town Health Office, Shashemene, Oromia Region, Ethiopia
}

\section{Email address:}

hailufekadu18@yahoo.com (H. Fekadu),bteshit@gmail.com (B. Teshite), g_teshome86@yahoo.com (G. Teshome), rozket@gmail.com (R. Amdemichael), mesfintafa2011@gmail.com (M. Tafa)

${ }^{*}$ Corresponding author

\section{To cite this article:}

Hailu Fekadu, Buli Teshite, Getu Teshome, Roza Amdemichael. Mesfin Tafa. Utilization of Emergency Contraception and Associated Factors Among Vocational College Female Students in Shashemene Town, Oromia, Ethiopia, 2018. American Journal of Clinical and Experimental Medicine. Vol. 8, No. 3, 2020, pp. 49-55. doi: 10.11648/j.ajcem.20200803.14

Received: May 19, 2020; Accepted: June 1, 2020; Published: June 20, 2020

\begin{abstract}
Background: Emergency contraception is a method to prevent unwanted or unintended pregnancies that could happen after unprotected sexual intercourse. It is a type of modern contraception that can be used following wrong use of contraception. In Ethiopia studies conducted in health facilities showed that unintended pregnancies and unprotected sexual intercourse are causing major reproductive health problems to adolescents. Objective: to assess the utilization of emergency contraception and associated factors among Technical and Vocational education training college female students in Shashemene town from June 10 - 30/2018. Method: an institution based cross-sectional study was conducted among Shashemene town Technical and Vocational education training college female students in June 2018. Collected data was entered into EPIINF version 7 and exported to SPSS version 21 for analysis. Association between dependent and independent variable was assessed using adjusted odds ratio with $95 \%$ confidence interval and p-value for statistical significance $(<0.05)$. Result: a total of 476 female students were participated in our study out of these, one hundred forty six (30.7\%) of the respondents knew presence of emergency contraception and $58(12.2 \%)$ of them had encountered unprotected sexual intercourse. Out of those who encountered unprotected sexual intercourse $42(72.4 \%)$ had used emergency contraception. However, 17 (29.3\%) of the respondents who reported unprotected sexual intercourse had history of unwanted pregnancy. Monthly family income was significantly associated with the utilization of emergency contraception (AOR $=4.41(95 \% \mathrm{CI}$ : 1.44-13.48)). Conclusion: Unprotected sexual intercourse and unwanted pregnancy were available among study participants. Knowledge of emergency contraception among the study participants was low.
\end{abstract}

Keywords: Unprotected Sexual Intercourse, Family Planning, Awareness

\section{Introduction}

Emergency contraception is a type of modern contraceptive method. There are two types of emergency contraception, these are: emergency contraceptive pills (ECPs) and intrauterine contraceptive device (IUCD). If used correctly, all types of ECPs can reduce the risk of unintended pregnancy and decrease unsafe abortion. [1-4] Usually this contraception is used after unprotected sexual intercourse. Emergency contraception prevents unwanted pregnancy when taken within 5 days after unprotected sexual intercourse. Female in reproductive age or stage can use emergency contraception after unprotected sexual intercourse to be protected from unintended pregnancy [1]. Emergency contraception should be administered as soon as possible after unprotected sexual intercourse. It is more effective if it is administered within 24 hours of unprotected sexual intercourse than delay more than 24 hours. $[2,3,5]$

How ever, the user of emergecy contraception has to know that lovonrgestrel containg emergecy contraception (LNG- 
EC) prevents pregnancy when taken before the ferilization of ovum has occurred [6]. Another thing that a user of the emergency contraceptive need to know is the following: according to prospctive cohort study conducted in 2008 early exposure to comboned oral contraceptive (COC) can reduce efficacy of ulipristal acetate (UPA) to use as an emergecny contraceptive [7].

There is also evidence that women who do not wish to conceive should be offered emergency contraception after unprotected sexual intercourse (UPSI) [8]. It may be possible that advance provision of emergency contraceptive to teenage girls can shorten the time interval from unprotected sexual intercourse to taking the contraceptive without increasing risk of pregnancy [9].

In the world 80 million out of 210 million pregnancies are unintended 75 million end in still birth and abortion [10]. Globally 529,000 girls and women die from pregnancy related causes each year out of that $13 \%$ are due to unsafe abortion and 2 out of 5 unsafe abortions occur among women under age 25 [10].

In developing countries $56 \%$ of all abortions are unsafe. In Africa $42 \%$ of all pregnancies were unintended. In east African countries 2.5 million (39.1\%) induced abortions occurred in 2008 out of all induced abortions in Africa. This is percent is higher than any other countries in Africa. Teenage pregnancies are high in Ethiopia with 187/1000 [11].

Mortality of women age between 15 and 49 is $30 \%$ in Ethiopia. This percent puts the country among the countries with high mortality of this age group [12]. In Ethiopia 47\% of abortions performed outside health facilities that cause major reproductive health problems among adolescents and women and among unsafe abortions unintended pregnancies accounted $49.1 \%$ and non-use of contraceptive method accounted $78 \%$ of pregnancies $[4,13]$.

Study conducted in one of Ethiopian university (Mada Wolabu University) showed that prevalence of unintended pregnancy was about $32.4 \%$ [14].

Study done among Adama university female students showed that $27.2 \%$ and $62.9 \%$ students had good and favorable attitude respectively. Among these students the study found $4.7 \%$ utilized emergency contraception [15]. Study done among Jimma university graduating female students revealed that $41.9 \%$ of the participants aware of emergency contraception. Among the respondents $72.1 \%$ had favorable attitude and $6.8 \%$ were used the contraception [16]. Study on emergency contraception (EC) showed that twenty five percent of female students of Haramaya University had good knowledge and $47 \%$ were used emergency contraception among the study participants [17]. Study done among Hawassa university female students indicated that $72.2 \%$ had awareness and $10.8 \%$ had used the emergency contraception [18]. Study conducted among Debrae Markos university female students found that among $54974.9 \%$ had awareness, $48.5 \%$ had favorable attitude and $18.4 \%$ had used emergency contraception [19].

Study conducted among female students of Fasiledes preparatory school showed good knowledge of emergency contraception among the students were $69.4 \%$ and those who used the method were $13 \%$ [20].

Survey conducted in Mizan -Tepi University found that $43.1 \%$ of unwanted pregnancies occurred out of those $46.3 \%$ were due to unprotected sexual intercourse [21]. According to the study conducted among Hawassa university students $39.7 \%$ of all participants were escaped from forced sexual attempt and $2.2 \%$ were experienced unprotected sexual intercourse [18].

Study conducted among female students of Jimma University showed that awareness of emergency contraception was associated with the origin of residence [16].

As we can see from the above studies conducted in different areas among female students of universities, Colleges or preparatory schools in Ethiopia indicated that unintended pregnancy, unsafe abortion, unprotected sexual intercourse, attempt of forced sexual intercourse, experience of forced sexual intercourse and utilization of emergency contraception (EC) have different magnitude. These indicate utilization and factors associated with the utilization of emergency contraception may have different magnitude among different colleges or places. That is why we conducted this study.

\section{Materials and Methods}

\subsection{Study Area and Period}

The study was conducted in Shashemene town that is found in west Arsi zone, Oromia regional state, Ethiopia. Shashemne is $250 \mathrm{KM}$ from Addis Ababa (capital city of Ethiopia). The projected total population of Shashemene town is about 264,780 out of which 131,952 and 132,828 are males and females respectively in 2017/18. About 92,673 are adolescents in the same year.

There are 2 functional governmental and 1 Private Hospital, 4 governmental and 1 non-governmental health centers. The health service coverage of the town by the health center is $71.4 \%$. There are 3 private University Colleges, 1 TVET College and 3 Preparatory Schools in Shashemene town.

Shashemene TVET College is found in Shashemene town. The college has four main sectors namely, Economic Infrastructure sector (12 departments), Industry development sector (6 departments), Agriculture sector (9 departments) and Culture, Sport \& Tourism sector ( 9 departments) sectors. Recently for the year 2017/2018 admission documents shows a total of 6613 regular students out of them, 3973 are females'. The study will be conducted from June, 10/2018 June, 30/2018.

\subsection{Study Design}

A quantitative community based cross-sectional study design, supplemented by qualitative data was conducted. 


\subsection{Source Population}

All female TVET college students of Shashemene Town found on admission records in the year 2017/2018.

\subsection{Study Population}

All female TVET college students those were randomly selected for this study.

\subsection{Sample Size}

The required sample size was determined by using single population proportion formula. We used the proportion of students who utilized emergency contraception (18.4\%) from the study conducted among the female students of Debra Markos higher institution, North West Ethiopia. ${ }^{19}$ Considering 5\% margin of error and $95 \%$ confidence interval and design effect of 2 with $10 \%$ non-response rate the final sample size was 480 .

\subsection{Data Collection Procedures}

Data collection instrument was self administered questionnaire. It was developed in English and translated to Afan Oromo and back to English for the purpose of consistency. The questions were arranged and grouped according to the particular objectives that they can address all important variables of the study. The questionnaire was pretest on 5\% (24) of similar participants. The self administered questionnaires were offered to the study participants in quiet rooms. Data was collected by four (04) teachers and two (02) Nurse Supervisors.

Qualitative data was collected from purposely selected key informants based on their experience in their respective health institutions and willingness to participate. In-depth interview method was used to collect the data. During the interview the data collectors took notes by the participants own word.

\subsection{Data Quality Assurance}

Data collectors were trained for two days and they practiced data collection. The purpose of the study was adequately explained to the participants. The participants were assured that the confidentiality of the collected data will be kept moreover; they were informed that they should not write their names on the question paper. A problem that may face during data collection was discussed with their solutions. After data collection had completed each questionnaires were checked visually for completeness of all variables in the questionnaires. Data clerks were carefully selected to employ for double data entry. The two sets of entered data were compared and inconsistent data were corrected.

\subsection{Data Analysis and Processing}

The collected data was entered into EPIINFO 7, and was exported to SPSS (statistical product and service solutions) version 21 for analysis. Frequency, percentage, measures of variation and mean were used to describe the study population in relation to relevant variables.

Binary logistic regression was performed for each variable and then all variables were entered into binary logistic regression at once to control the potential confounding variables. Crude and adjusted odds ratio, 95\% CI and Pvalues for statistical significance were used to see the association between variables. Finally the findings were presented by text and tables.

The qualitative data was organized into thematic area after the data is collected from the key informants.

\subsection{Ethical Consideration}

Ethical clearance was obtained from Arsi University, College of health sciences, Department of Public health. Permission letter was obtained from Oromia regional health Bureau and Shashemene town. All study participants were informed about aim of the study. Consent paper was obtained from study participants.

\section{Result}

\subsection{Scio-Demographic Characteristics of Respondents}

A total of 480 self-administered questionnaires were distributed to the study participants however the response were obtained from 476 students. The response rate was $99.2 \%$. The mean age of the study participants found to be $18.63(+1.38)$ ranging from $15-25$ years old. Four hundred thirty $(90.3 \%)$ of the respondents age range were from $17-20$ years. The age distribution of respondents showed that 381 $(80.04 \%)$ were $15-19$ years of age.

More than seventy three percent $350(73.5 \%)$ were Muslim and majority 454 (95.4\% were single. More than half 281 $(59 \%)$ of the respondents were from rural. About 208 (43.7\%), 169 (35.5\%), 79 (16.6\%), 13 (2.7\%) and 7 (1.5\%) were live with parents, live with peer in rental house, live alone in rental house, live with their husband and boyfriends respectively. Majority of the respondents' father 324 (68.1\%) and Mother 287 (60.3\%) occupation were farmer (Table 1).

Table 1. Scio-demographic characteristics of studied population $(n=476)$.

\begin{tabular}{lllll}
\hline variable & & frequency & percent \\
\hline & $15-19$ & 381 & 80.04 \\
Age in year $(\mathrm{n}=476)$ & $20-24$ & 94 & 19.75 \\
& $25-29$ & 1 & 0.21 \\
& Oromo & 433 & 91 \\
Ethnicity $(\mathrm{n}=476)$ & Amhara & 23 & 4.8 \\
& Others & 20 & 4.2 \\
\hline
\end{tabular}




\begin{tabular}{llll}
\hline variable & & frequency & percent \\
\hline \multirow{3}{*}{ Religion $(\mathrm{n}=476)$} & Muslim & 350 & 75.3 \\
& Orthodox & 86 & 18.1 \\
& protestant & 33 & 6.9 \\
& Others & 7 & 1.47 \\
& Single & 45.4 & 3.4 \\
Marital status $(\mathrm{n}=476)$ & married & 16 & 0.4 \\
& divorced & 2 & 0.8 \\
& separated & 41 \\
Residence $(\mathrm{n}=476)$ & Urban & 4 & 59 \\
& Rural & 195 & 43.7 \\
& Parents & 281 & 35.5 \\
Recently living with $(\mathrm{n}=476)$ & Peers in rental house & 208 & 16.6 \\
& Alone in rental house & 169 & 2.7 \\
Family monthly income $(\mathrm{n}=476)$ & husband & 79 & 1.5 \\
& Boy friend & 13 & 37.6 \\
\hline
\end{tabular}

\subsection{Sexual and Reproductive Characteristics of Respondents}

Out of the total participants of this our study 58 (12.2\%) of the respondents have had unprotected sexual intercourse. The overall prevalence of unwanted pregnancies among those who had unprotected sexual intercourse were 17 (29.3\%) while $3.8 \%$ from the total respondents (Table 2 ).

Table 2. Sexual and reproductive history of studied population $(n=476)$.

\begin{tabular}{llll}
\hline variable & & frequency & percent \\
\hline Unprotected sexual & no & 418 & 87.8 \\
intercourse $(\mathrm{n}=476)$ & yes & 58 & 12.2 \\
& $10-14$ & 6 & 10.3 \\
Age of first sexual & $15-19$ & 49 & 84.5 \\
intercourse $(\mathrm{n}=58)$ & 20 and above & 3 & 5.2 \\
& yes & 17 & 29.3 \\
History of unwanted & no & 41 & 70.7 \\
pregnancy $(\mathrm{n}=58)$ & &
\end{tabular}

\subsection{Respondents' Awareness and Utilization of Emergency Contraception}

Out of the total participants of this study $146(30.7 \%)$ participants reported that they know the presence of emergency contraception. Out of 146 participants who knew presence of emergency contraception $42(28.8 \%)$ had utilized emergency contraception. Knowledge of effective timing of emergency contraception among 146 participants who respond for effective timing of emergency contraception was as follows: twenty (14\%) said they don't know the effective time of taking emergency contraception and $15(10 \%)$ said emergency contraception is effective if taken at any time.

Out of 158 participants who respond to reasons of not used emergency contraception $59 \quad(37 \%)$ and $72 \quad(46 \%)$ respondents said that service inconvenient and belief that it is not effective were the reasons for not using emergency contraception respectively (Table 3 ).

Table 3. Awareness and utilization of emergency contraception among studied population ( $n=476)$.

\begin{tabular}{|c|c|c|c|}
\hline Variables & & Frequency & Percent \\
\hline \multirow{2}{*}{ Know presence of emergency contraception $(n=476)$} & no & 330 & 69.3 \\
\hline & yes & 146 & 30.7 \\
\hline \multirow{4}{*}{ Knowledge of effective timing of emergency contraception } & Within 5 days & 96 & 66 \\
\hline & Within one week & 15 & 10 \\
\hline & Any time possible & 15 & 10 \\
\hline & I don't know & 20 & 14 \\
\hline Used emergency contraception $(n=146)$ & no & 104 & 71.2 \\
\hline \multirow{2}{*}{$\begin{array}{l}\text { Willingness to use emergency contraception in the future } \\
(\mathrm{n}=476)\end{array}$} & no & 158 & 33.2 \\
\hline & yes & 318 & 66.8 \\
\hline \multirow{4}{*}{ Reasons for not used emergency contraception $(n=158)$} & Fear of being seen by relatives & 16 & 10 \\
\hline & Service inconvenient & 59 & 37 \\
\hline & Belief that it is not effective & 72 & 46 \\
\hline & I don't know & 11 & 7 \\
\hline
\end{tabular}

\subsection{Key Informant Interview (KII)}

Nine individuals were involved purposely in order to get information from different health institutions. The themes of each respondent were taken as important point for this study. One informants from Pharmacy, 1 from Health Center, Hospital service provider (02), Family guidance association 
(FGAE) (1) DKT (1) TVET college teachers (02) Town health office (01) were participated.

Almost all respondents said; EC pill namely "mela one" is commonly available in almost all pharmacy, FGAE clinics and drug stores. Respondent from TVET College suggests "it is good if the government avail the reproductive health service point including EC in the college compound".

Almost all key informants have, mentioned most of the users were youths of college students;

Respondents from FGAE and pharmacy said: 'the reason why users mostly prefer to get the service from pharmacy despite the cost is because they don't want to wait and seen by others; when they go to Hospital, $\mathrm{HC}$ and Clinic there is a time to wait for card and examination procedure, but when they go to pharmacy/drug stores simply they ask for "mela one" and get the service".

A respondent from FGAE clinic said "it is good, making the service free of charge at any service point, to maximize the service, including private pharmacy/drug store, because it is costly for student users to purchase it twenty five $(25: 00)$ Ethiopian birr from pharmacy/drug store"

Respondent from TVET College said "it is good if the government include reproductive health course which include $\mathrm{EC}$, in TVET college curriculum".

\subsection{Factors Associated with Utilization of Emergency Contraception of Respondents}

The variables were entered into binary logistic regression and the following variables were significant in the regression: age of first menarche, having boyfriends, ever had sexual intercourse, forced into sexual intercourse and escaped, frequency of forced sexual intercourse, ever used modern family planning method, willingness to use emergency contraception in the future, respondents' mother educational status and family monthly income. These factors were included in the multivariate logistic regression.

Finally, factors remained significantly associated with utilization of emergency contraception in multivariate logistic regression were forced sexual attempt, used modern family planning, willingness to use emergency contraception and family monthly income. Respondents who escaped three times and above from forced sexual attempt were about seven times more likely to utilize EC compared respondents who escaped one time from forced sexual attempt $(\mathrm{AOR}=6.66(95 \% \mathrm{CI}$ : 1.93-18.97)). Responds that have monthly income of 20004000 Ethiopian birr were about 4 times more likely to utilize emergency contraception compared to respondents who have monthly income of $<2000$ Ethiopian birr $(\mathrm{AOR}=4.41(95 \% \mathrm{CI}$ : 1.44-13.48)) (Table 4).

Table 4. Predictors of emergency contraception utilization among studied population ( $n=476)$.

\begin{tabular}{|c|c|c|c|c|c|}
\hline Variable & & COR & $95 \% \mathrm{CI}$ & AOR & $95 \% \mathrm{CI}$ \\
\hline \multirow{3}{*}{$\begin{array}{l}\text { Number of escape from forced sexual } \\
\text { attempts }\end{array}$} & One time & & & 1 & \\
\hline & Two times & 1.66 & $0.55-5.04$ & 1.09 & $0.27-4.32$ \\
\hline & Three and above & 3.45 & $1.40-8.49$ & 6.66 & $1.93-18.97 *$ \\
\hline \multirow{2}{*}{ Used modern family planning method } & No & & & 1 & \\
\hline & Yes & 0.10 & $0.03-0.31$ & 0.08 & $0.02-0.29 *$ \\
\hline Willingness to use Emergency contraception & No & & & 1 & \\
\hline \multirow{3}{*}{ Family monthly income } & $<2000$ & & & & \\
\hline & $2000-4000$ & 2.04 & $0.85-4.92$ & 4.41 & $1.44-13.48^{*}$ \\
\hline & $>4000$ & 2.29 & $0.91-5.80$ & 3.62 & $1.13-11.58^{*}$ \\
\hline
\end{tabular}

Abbreviations: CI, Confidence Interval; EC, Emergency Contraceptive; TVET, Technical and Vocational Education Training; OR, Odds Ratio; AOR, Adjusted Odds Ratio.

\section{Discussion}

In our study a total of $74(15.5 \%)$ were reported that they have encountered forced sexual attempt. Study done among Hawassa university female students showed that $39.7 \%$ had experienced forced sexual attempt [18]. This difference could be due to the fact that Hawassa town is bigger than Shashemene town where this study was conducted since forced sexual attempt may be more prevalent in big towns.

In our study out of respondents who encountered unprotected sexual intercourse $17(29.3 \%)$ of them had unwanted pregnancy. However, survey conducted among Mizan -Tepi University students revealed that $43.1 \%$ have unwanted pregnancies [21]. This could be due to the fact that Mizan Tepi is remote area compared to Shashemene town where this study was conducted.

This study showed $146(30.7 \%)$ respondents have heard about EC. Similarly study conducted among Adama
University revealed that $27.2 \%$ of the universities female students have good knowledge of emergency contraception. [15] And another study on emergency contraception among Haramaya university female students showed that twenty five percent the respondents had good knowledge of the contraception [17]. However, study conducted in Jimma University among the university students (graduating) indicated that $41.9 \%$ of study participants have awareness about emergency contraception [16]. The difference between our study and that of Jimma University could be due to the fact that the study done in Jimma University is among graduating students those stayed in the campus for longer time than our study participants.

The study conducted in Jimma university found that students those did not aware about emergency contraception were more likely to have unfavorable attitude to use the contraception [16]. In this study willingness to use 
emergency contraception if they face unprotected sexual intercourse was $66.8 \%$. This percentage is lower than that of study conducted in Hawassa town among second cycle primary evening school that is $85 \%$ [22]. This difference may be due to the fact that our study is among regular students but the study in Hawassa is among evening students.

This study showed that utilization of EC was $(72.4 \%)$ among the respondents, this finding is much more than that of Mizan Tepi University (46.3\%) [21]. and a study conducted in Abdisa Aga high school [21]. The finding is also higher than that of finding of Debre Markos University $(18.4 \%)$ [19]. But much higher than that done in Jima University (6.8\%) [16]. Hawasa University (10.8\%). [18] and Seto Semoro high school (11.78\%) [24]. These differences among studies conducted in different areas may need further research however; it could be due to availability of information channels in respective areas. It may be due to the unjustifiable reason that women in developing countries may face challenge in accessing and provision of modern contraceptive to delay first birth if study conducted among young adolescent and married women of Tanzania in 2017 works for the rest of developing countries [25].

\section{Conclusion}

Finding from this study showed that utilization of EC was $72.4 \%$. However, unwanted pregnancy was $29.3 \%$ among the study participants and knowledge of emergency contraception among the study participants was $30.7 \%$. Factors significantly associated with the utilization of emergency contraception were forced sexual attempt three times and above, used modern family planning and monthly family income.

Strengthening awareness about emergency contraception among TVET College students and supporting female students financially may help to reduce unwanted pregnancy.

\section{Disclosure}

The authors declare no conflicts of interest in this work. All authors reported that no financial and all other conflicts of interest.

\section{Acknowledgements}

The author forwarded deepest thank to Shashemene town health office staff for their cooperation and willingness to provide valuable information for this study. The author extended the appreciation to all study participants, data collectors and supervisors.

\section{References}

[1] World Health Organiation. Family planning: a global handbook for providers: 2011 update evidence-based guidence developed through world wide collaboration. Cambodia: University research Co. LL (URC), 2011. Available from: http://apps.who.int/iris/handle/10665/44028. Accessed May 1, 2018.
[2] FSHR Clinical effectiveness unit. FSHR Clinical guideline: Emergency contraception (March 2017, amended December 2017). UK, 2017. Avaialble from: http://www.nice.org.uk/accreditation. Accessed June 7, 2018.

[3] European Consortium for Emeregency Contraception. An unpadet on access to emergency contraception in European countries, 2016. Availbale from: http://www.ecec.org/resources/publications. Accessed May 13, 2018.

[4] Ann M, Yirgu G, Tamirat F, et al. The Estimated Incidence of Abortion in Ethiopia, 2014: Changes in the Provision of Service since 2008. Int Perspect Sex Reprod Health. 2014; 42 (3). doi: https://doi.org/10.1363/42e1816[published].

[5] Piaggio G, Kappa N, Von Hertez H. Effect on pregnancy rates of the delay in the administration of lovonorgestrel for emergency contraception: a combined analysis of WHO trials. Contraception. 2011; $84 \quad$ (1): 35-9. doi: 10.1016/j.contraception.2010.11.010.

[6] Noe G, Croxatto HB, Salvatierra AM. Contraceptive efficacy of emergency contraception with levonorgestrel given before or after ovulation. Contraception. 2010; 81 (5): 414-20. doi: 10.1016/j.contraception.2009.12.015.

[7] Edelman AB, Jensen JT, McCrimmon S, Messerle-Forbes M, O'Donnell A, Hennebold JD. Combined oral contraceptive interference with the ability of ulipristal acetate to delay ovulation: A prospective cohort study. Contraception. 2018. doi: 10.1016/j.contraception.2018.08.003.

[8] Liambila N, Saumya R, Joyce W, Mary W; for The Population Council, Inc. Mainstreaming Emergency Contraception in Developing Countries: A Toolkit for Policymakers and Service Providers. Nairobi: Population Council. Nairobi, Kenya. 2013. Available from: http://www.popcouncil.org/. Accessed June 3, 2018.

[9] Ekstrand M, Larsson M, Darj E, Tyden T. Advance provision of emergency contraceptive pills reduces treatment delay: a randomised controlled trial among Swedish teenage girls. Acta Obstet Gynecol Scand. 2008; 87 (3): 354-9. doi: $10.1080 / 00016340801936024$.

[10] Department of Reproductive Health and Research, World Health Organization. Unsafe abortion: global and regional estimates of the incidence of unsafe abortion and associated mortality in 2008. 2008. Available from: https://apps.who.int/iris/bitstream/handle/10665/44529/97 89241501118_eng.pdf? sequence $=1$ Accessed June 1, 2018.

[11] Sedgh G, Finer LB, Bankole A, Eilers MA, Singh S. Adolescent pregnancy, birth, and abortion rates across countries: levels and recent trends. J Adolesc Health. 2015; 56 (2): 223-30. https://doi.org/10.1016/j.jadohealth.2014.09.007.

[12] Central Statistical Agency - CSA/Ethiopia, ICF. Ethiopia Demographic and Health Sruvey 2016. Addis Ababa, Ethiopia: CSA and ICF; 2017. Available from: http://dhsprogram.com/pubs/pdf/FR328/FR328.pdf. Accessed May 12, 2018.

[13] Tekle-Ab M, Yirgu G, Misganaw F. Survey of Unsafe Abortion in Selected Health Facilities in Ethiopia. Ethiopian Journal of Reproductive Health. 2007; 1 (1): 28-23. Available from: https://www.researchgate.net/publication/281232397. Accessed March 3, 2018. 
[14] Getachew M, Kerbo A. Unwanted Pregnancy and Associated Factors among Female Students of Madawalabu University Bale Zone, Oromia Region South East, Ethiopia. Science Journal of Public Health. 2015; 3. doi: 10.11648/j.sjph.20150301.19.

[15] Aman J, Mesfin T, Ababi Z. Assessment of Knowledge, Attitude and Utilization of Emergency Contraception among Unmarried Women of Reproductive Age in Adama, Ethiopia. Health Science Journal. 2016; 10 (6). doi: 10.21767/1791809X.1000469.

[16] Tajure N, Pharm B. Knowledge, attitude and practice of emergency contraception among graduating female students of jimma university, southwest ethiopia. Ethiop J Health Sci. 2010; 20 (2): 91-97.

[17] Berhanu D, Nigatu R. On Emergency Contraception among Female Students of Haramaya University, Ethiopia: Surveying the Level of Knowledge and Attitude. Educational Research. 2011; 2 (4): 1106-17. Available from: http://www.interesjournals.org/ER. Accessed May 1, 2018.

[18] Ejara T, Birhanu A, Amanuel AA. Assessment of level of knowledge and utilization of emergency contraception among female students of Hawassa University, South Ethiopia Advances in Reproductive Sciences. 2013; 1 (3): 51-56. doi: http://dx.doi.org/10.4236/arsci.2013.13008.

[19] Habtamu A, Mulatu M, Dube J. Knowledge, Attitude, Utilization of Emergency Contraceptive and Associated Factors among Female Students of Debre Markos Higher Institutions, Northwest Ethiopia, 2014. Fam Med Medl Sci Res. 2014; 3 (4). doi: https://doi.org/10.4172/23274972.1000149 .
[20] Gebremedhin K, Gebresillassie T, Demeke T, Habtie N. Assessment of Knowledge, Attitude and Behaviour towards Emergency Contraceptive among Female Students of Fasiledes Preparatory School, Gondar, Ethiopia. Clin in Mother Child Health. 2017; 14 . doi: 10.4172/20907214.1000260 .

[21] Shiferaw B, Gashaw B, Tesso F. Factors associated with utilization of emergency contraception among female students in Mizan-Tepi University, South West Ethiopia. BMC Res Notes. 2015; 8 (1): 817. doi: 10.1186/s13104-015-1812-6.

[22] Alemayehu A, Teferi G. Awareness and Utilization of Emergency Contraceptives Among Second Cycle Primary School Female Evening Students in Hawassa, Ethiopia: A Cross-Sectional Survey. Ethiopian Pharmaceutical Journal. 2016; 32 (1). doi: http://dx.doi.org/10.4314/epj.v32i1.6.

[23] Abebe F. Assessment of Knowledge, Attitude and Practice Towards Emergency Contraceptive Methods among Female Students in Abdisa Aga High School, Fiche Town, Northern, Ethiopia, 2016. International Journal of Chinese Medicine. 2017; 1 (1): 16-23. doi: 10.11648/j.ijcm.20170101.13.

[24] Asmare T, Asmamaw D, Temamen T, Addis A, Yonas Y, Birhan A. Assessment of Knowledge, Attitude and Practice towards Emergency Contraceptive Methods among Female Students in Seto Semero High School, Jimma Town, South West Ethiopia. Science Journal of Public Health. 2015; 3 (4): 478-86. doi: 10.11648/j.sjph.20150304.15.

[25] Sedekia Y, Jones C, Natan R, Schellenberg J, Marchant T. Using contraceptives to delay first birth: a qualitative study of individual, community and health provider perceptions in southern Tanzania. BMC Public Health. 2017; 17 (1): 768. doi: 10.1186/s12889-017-4759-9. 